\title{
Correction to: Resection of Isolated Pelvic Recurrences after Colorectal Surgery: Long-Term Results and Predictors of Improved Clinical Outcome
}

Leonard R. Henry, $\mathrm{MD}^{1}$, Elin Sigurdson, $\mathrm{MD}, \mathrm{PhD}^{1}$, Eric A. Ross, $\mathrm{PhD}^{2}$, John $\mathrm{S}$. Lee, $\mathrm{MD}^{1}$, James C. Watson, $\mathrm{MD}^{1}$, Jonathan $\mathrm{D}$. Cheng, $\mathrm{MD}^{3}$, Gary M. Freedman, $\mathrm{MD}^{4}$, Andre Konski, $\mathrm{MD}^{4}$, and John P. Hoffman, $\mathrm{MD}^{1}$

${ }^{1}$ Department of Surgical Oncology, Fox Chase Cancer Center, Philadelphia, Pennsylvania ; ${ }^{2}$ Department of Biostatistics, Fox Chase Cancer Center, Philadelphia, Pennsylvania ; ${ }^{3}$ Department of Medical Oncology, Fox Chase Cancer Center, Philadelphia, Pennsylvania ; ${ }^{4}$ Department of Radiation Oncology, Fox Chase Cancer Center, Philadelphia, Pennsylvania

\section{CORRECTION TO:}

ANNALS OF SURGICAL ONCOLOGY

14(3):1081-1091

HTTPS://DOI.ORG/10.1245/S10434-006-9266-7

The 2006 article entitled, "Resection of Isolated Pelvic Recurrences after Colorectal Surgery: Long-Term Results and Predictors of Improved Clinical Outcome" was pub- lished with two unique digital identifier numbers (DOI) in error. To address this, the https://doi.org/10.1245/s10434006-9266-7 is now only associated with this article.

DOI https://doi.org/10.1245/s10434-006-9343-y is no longer associated with this article.

The original article can be found online at https://doi.org/10.1245/s10434-006-9266-7.

(C) Society of Surgical Oncology 2020

Published Online: 25 November 2020

J. P. Hoffman, MD

e-mail: JP_Hoffman@fccc.edu 